\title{
Egyptian Journal of Chemistry
}

\author{
http://ejchem.journals.ekb.eg/
}

\section{Impact of magnesium, zinc, selenium, copper, and iodine food supplements on SARS-CoV, SARS-CoV-2 viruses and their adducts with human ACE2 enzyme: A Computational Based Investigation}

\author{
M. S. A. Abdel-Mottaleb ${ }^{\mathbf{1}}$ and Yousra Abdel-Mottaleb ${ }^{\mathbf{2}}$ \\ ${ }^{1}$ Department of Chemistry, Faculty of Science, Ain Shams University (ASU), Abbassia 11566, Cairo, Egypt \\ ${ }^{2}$ Department of Pharmacology, Toxicology, and Biochemistry, Faculty of Pharmaceutical Sciences and \\ Pharmaceutical Industries, Future University in Egypt (FUE), New Cairo 11835, Egypt
}

\begin{abstract}
In a search for drugs of the potential impact on SARS-CoV and SARS-CoV-2, we have chosen different forms of metal-based food supplements to investigate. We computed their binding to specific peptide sequences of the spike virus S-protein: angiotensin-converting enzyme 2 (ACE2) interface-drug binding adduct. Manual docking was applied. The chosen molecules located themselves to achieve minimum energy geometries, resulting in limiting the viral recognition of the host cells or disturbing the host-virus interactions. Based on the HOMO - LUMO frontier orbitals, we successfully used the computed reactivity indices to explain the simulation results. The results are compared with that similarly simulated interactions between the protein/protein and the experimentally allowed remdesivir drug that has been granted emergency use authorization by the FDA. These computationally based findings also suggest that the simple computational indices and methods could point to promising medicines to help with the fight against COVID-19. However, in vivo and in vitro, experimental validation is now required.
\end{abstract}

Keywords: Viral S proteins, Food supplements, Organometallics, Frontier orbitals, Reactivity indices, Binding energy

\section{1- Introduction}

Using computational models or simulation is the first step in drug finding. Drug design is the artistic process of finding new drugs based on the familiarity of a biological target. In the most basic sense, medicine design involves the proposal of molecules of suitable shapes and charge to the molecular target with which they interact and bind. We have chosen some elements such as magnesium, copper, zinc, selenium, and iodine, which are micronutrients in our diet, which are necessary to sustain optimal biological functions [1-3] and optimal immune responses to infections, including viral ones [4].

Copper plays a fundamental role in immunity by participating in the development and differentiation of immune cells and directly affecting viral infections [5]. Zinc participates in the maintenance of immune function, and its deficiency has been linked to increased susceptibility to viral infections [6]. Another trace element, selenium, is necessary for many physiological purposes [7]. Low selenium status has been associated with poor immune function, while a higher selenium concentration of selenium supplementation has shown antiviral effects [7]. Magnesium L-threonate supports memory and overall cognitive function [8].

Iodine is a general antiseptic that can cripple viruses, bacteria, fungi, and spores. Iodine proved effective against a multitude of illnesses such as influenza, herpes, chicken, and smallpox. [9-15] Studies have suggested the use of iodine orally to prevent/treat viral infections. This suggestion is backed by the already established use of iodine in treating thyroid disorders [16].

Earlier studies on some drugs and nutraceuticals that show potential benefits in the treatment/prevention of the COVID-19 pandemic have been proposed [17]. Here we will carry out a computational simulation of the interactions between a simple $S$ protein sequence representing the SARS$\mathrm{CoV}$ virus with drugs and with ACE2. We will calculate the binding energies of the formed adducts.

*Corresponding author e-mail: m.s.abdelmottaleb@sci.asu.edu.eg.; (M. S. A. Abdel-Mottaleb).

Receive Date: 14 August 2020, Revise Date: 28 September 2020, Accept Date: 04 October 2020

DOI: 10.21608/EJCHEM.2020.39235.2802

(C2021 National Information and Documentation Center (NIDOC) 
We will identify the mechanism of the interactions that will lead to the further development of promising molecules, which can be efficiently utilized to take the virus down. Furthermore, recently, a molecular docking study was reported which identified small molecules that bind to either the isolated Viral Sprotein at its host receptor region or to the $S$ proteinhuman ACE2 interface using the world's most powerful supercomputer, SUMMIT.[18] Moreover, the reactivity indices of the interacting molecules were not identified or discussed.

Our objective is to explore the potential of commercially available food supplements known to act as immunity enhancers towards the previous SARS-CoV and new virus SARS-CoV-2. Through our work reported here, we are studying in a simplified way the binding ability of seven medications of some food supplement formulations to rush the discovery of improved treatment choices, thus paving the way to a hopefully near future removal of the COVID-19 epidemic. To spare time and computational cost, we first broadly consider the earlier coronavirus $S$ protein that is homologous in many aspects with SARS-CoV-2. We will then refine the results using only promising materials of the preliminary communication with the previous SARS$\mathrm{CoV}$. We will then simulate their influence on the $\mathrm{S}$ protein of SARS-CoV-2, which is identified recently as the beta-sheet sequence $\left(\beta_{6}\right)$ that contains most of the contacting strand of SARS-CoV-2 that binds to ACE2 [19].

To provide supportive information to our findings, the results obtained will be compared with that similarly simulated interactions between the protein/protein and the experimentally allowed remdesivir drug that has been granted emergency use authorization by the FDA.

The results we reported are the first step towards the identification of the importance of the electronic characteristics such as electrophilicity $(\omega)$ (based on the chemical potential $(\mu)$ and hardness $(\eta)$ indices ) and nucleophilicity (N) [20 - 26] of the drugs and utilization in treatments with potentially low-risk side effects relative to the current insufficient high-risk treatment options against COVID-19.

\section{1- Simulation Methodology}

The equilibrium geometry of the interacting molecules was obtained by applying the molecular mechanics' method built-in Spartan 18 parallel suite (core > 16) package offered by www.Wavefun.com at reduced prices due to COVID-19 lockdown. Single-point computations are then applied to the molecular mechanically optimized equilibrium geometry with DFT using the long-range corrected hybrid density functional, the wB97X-D functional [27], which includes empirical damped atom-atom dispersion corrections with 6-31G(d) and LANL2DZ $>\mathrm{Kr}$ basis sets [28]. The method used is efficient and cost-effective for capturing information across biological scales. The useful reaction field model used for solvation (water) is the conductor-like polarizable continuum model (CPCM), which performs a PCM (polarized continuum model) calculation [29].

\section{2- Results and Discussion}

In the present study, we followed the same way reported previously [17] to compute the binding energy (BE) using the well-known equation:

$\mathrm{BE}_{\text {adduct }}=\mathrm{E}_{\text {adduct }}-\left(\boldsymbol{\Sigma} \mathrm{E}_{\text {interacting species }}\right)$

The results are summarized in Tables 1 and 2. Table 1 shows the frontier orbital HOMO -- LUMO energy values and the well-known reactivity indices that reveal the electronic donor-acceptor reactivity of the individual ligands and ACE2 [30] - S protein adduct $[31,32]$.

As a supportive guide to our proposed methodology, we similarly simulated the interactions between remdesivir and the protein/protein. The experimental antiviral remdesivir assisted people with COVID-19 recover quicker, according to partial data released from a pilot led by the US National Institute of Allergy and Infectious Diseases. The data were adequate for the US Food and Drug Administration to allowance the experimental drug an emergency use authorization (EUA). This status will permit it to be used by doctors treating COVID-19 and be added to government supplies.

The stabilities of the adducts given in Table 2 stem from hydrogen bond formation and other electrostatic attractive/repulsive forces due to the intermolecular HOMO - LUMO electron transfer capabilities between the interacting molecules. Figures 1-5 represent the intermolecular interactions between ACE2 and the $\mathrm{S}$ protein and the promising drug molecules and the ACE2-S protein adducts using the HOMO (solid surface) and LUMO (mesh surface). 
Table 1- Reactivity indices (eV) of the individual ligand molecules, ACE2, S protein together with the ChemSpider ID, and the protein sequences of the S protein and ACE2.

\begin{tabular}{|c|c|c|c|c|c|c|c|}
\hline Free Drug/Target Protein & HOMO & LUMO & $\mu$ & $\eta$ & $\omega$ & $\mathrm{N}$ & $\begin{array}{l}\text { ID: } \\
\text { ChemSpider/Protein } \\
\text { sequence }\end{array}$ \\
\hline S protein (SARS-CoV) & -7.24 & 1.49 & -2.88 & 4.37 & 0.95 & 3.95 & $\beta$-sheet: KWGD \\
\hline S protein (SARS-CoV2) & -7.81 & 1.01 & -3.40 & 4.41 & 1.31 & 3.38 & $\begin{array}{l}\beta_{6} \text {-sheet: } \\
\text { YFPLQSYGFQ }\end{array}$ \\
\hline zinc gluconate & -7.84 & 1.02 & -3.41 & 4.43 & 1.31 & 3.35 & 391659 \\
\hline selenomethionine & -7.86 & 2.12 & -2.87 & 4.99 & 0.83 & 3.33 & 14375 \\
\hline remdesivir & -8.02 & 0.78 & -3.62 & 4.40 & 1.49 & 3.17 & 58827832 \\
\hline ACE2 & -8.08 & 1.18 & -3.45 & 4.63 & 1.29 & 3.11 & $\begin{array}{l}\text { ×-helical: } \\
\text { HEGPLHK }\end{array}$ \\
\hline sodium selenite & -8.18 & 0.86 & -3.66 & 4.52 & 1.48 & 3.01 & 1059 \\
\hline selenodiglutathione & -8.21 & -6.35 & -7.28 & 0.93 & 28.49 & 2.98 & 97171 \\
\hline magnesium L-Threonate & -8.96 & 1.81 & -3.58 & 5.39 & 1.19 & 2.23 & 24590125 \\
\hline iodine & -9.12 & -2.04 & -5.58 & 3.54 & 4.40 & 2.07 & 785 \\
\hline Copper sulfate & -9.69 & 0.65 & -4.52 & 5.17 & 1.98 & 1.50 & 22870 \\
\hline
\end{tabular}

Table 2- Reactivity indices (eV) of the Drug- ACE2-S protein adducts and the ACE2 - S protein (SARS$\mathrm{CoV}$ ) adducts and their binding energies (BE in kcal/mol)

\begin{tabular}{llllllll}
\hline Complexed Drug-ACE2-S protein & HOMO & LUMO & $\boldsymbol{\mu}$ & $\boldsymbol{\eta}$ & $\boldsymbol{\omega}$ & $\mathrm{N}$ & $\mathrm{BE}$ \\
selenodiglutathione & -7.82 & -5.14 & -6.48 & 1.34 & 15.67 & 3.37 & -122.26 \\
Iodine & -7.32 & -1.92 & -4.62 & 2.70 & 3.95 & 3.87 & -50.56 \\
copper sulfate & -7.24 & -1.20 & -4.22 & 3.02 & 2.95 & 3.95 & -30.83 \\
remdesivir & -7.46 & 0.23 & -3.62 & 3.85 & 1.70 & 3.73 & -15.29 \\
\hline zinc gluconate & -7.25 & 0.99 & -3.13 & 4.12 & 1.19 & 3.94 & -18.46 \\
ACE2-SARS-CoV S protein & -7.32 & 1.19 & -3.07 & 4.26 & 1.10 & 3.87 & -37.76 \\
magnesium L-Threonate & -7.29 & 1.19 & -3.05 & 4.24 & 1.10 & 3.90 & -72.71 \\
Selenomethionine & -7.21 & 1.20 & -3.01 & 4.21 & 1.08 & 3.98 & -36.73 \\
sodium selenite & -7.16 & 1.18 & -2.99 & 4.17 & 1.07 & 4.03 & -79.12 \\
\hline
\end{tabular}

The electrophilicity index $\left(\omega=\mu^{2} /(2 * \eta)\right.$ of a ligand measures its ability to act as an electron sink. The higher its value, the stronger is the electron sink property of a ligand. The data listed in Table 1 reveal that the electrophilicity strength increases in the order: selenomethionine $<\mathrm{S}$ protein $<$ magnesium Lthreonate $<$ ACE2 < zinc gluconate $<\mathrm{S}$ protein $(\mathrm{SARS}-\mathrm{CoV} 2)<$ sodium selenite < remdesivir < copper sulfate $<$ iodine $<$ selenodiglutathione.

The nucleophilicity index $[22,23]$ decreased in the order: $\mathrm{S}$ protein $(\mathrm{SARS}-\mathrm{CoV})>\mathrm{S}$ protein $($ SARS-CoV2) $>$ zinc gluconate $>$ selenomethionine
$>$ remdesivir > ACE2 > sodium selenite > selenodiglutathione > magnesium L-Threonate > iodine > copper sulfate. Remdesivir is a better electrophile than ACE2 and both S proteins. Whereas both $\mathrm{S}$ proteins are of enhanced nucleophilicity than remdesivir.

Both indices are pointing to copper sulfate, iodine, and selenodiglutathione as the best electrophiles (acting as durable electron sinks or scavengers), whereas zinc gluconate is the best nucleophile. Electronically, remdesivir behaves 
similarly. Figures 2 and 3 indicate the role played by these materials as durable electron sinks.

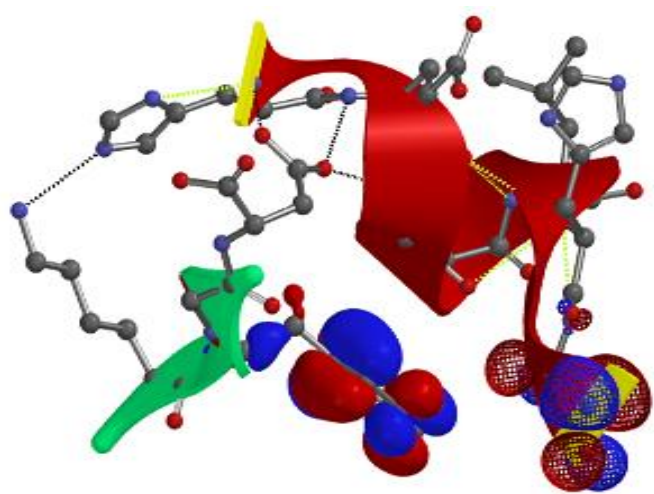

Figure 1. SARS-CoV S protein ( $\beta$-sheet: KWGD) (donates electrons (HOMO (solid)) to the ACE2 $(\propto$ helical: HEGPLHK) LUMO (mesh surface) forming the stable adduct $(\mathrm{BE}=-37.76 \mathrm{kcal} / \mathrm{mol})$. Dotted lines represent the formed hydrogen bonds.

The effect of complex formation between a drug molecule and the ACE2-S protein adduct is reflected in lowering the chemical potential, hardness, and electrophilicity of the formed complex. The nucleophilicity is enhanced by complexation. The operative intermolecular electronic interactions due to complexation, which results in a significant destabilization of the HOMO of the drugs and negligibly disturbs the LUMO, explain the alteration of these indices upon complexation.

Inspection of Table 2 clearly shows that the presence of any one of the following drugs, selenodiglutathione, copper sulfate, sodium selenite, magnesium L-threonate, or iodine results in enhancing the stability of the drug - ACE2 - S protein complex relative to the BE of ACE2 and $\mathrm{S}$ protein adduct. However, only iodine, copper sulfate, or selenodiglutathione adduct with the ACE2 - S protein result in the inhibition of the electronic communications between the ACE2 and the S protein. Figures 3, 4, and 5 show the donor-acceptor intermolecular electronic interactions between the drug and the target in their associations. Copper sulfate has the highest nucleophilic character $(5.4 \mathrm{eV})$ among all the molecules studied, thus enabling it to deactivate the $\mathrm{S}$ protein and thus shield the ACE2. Finally, selenomethionine or zinc gluconate complexes with the ACE2-S protein adduct are weaker than the ACE2-S protein adduct. Besides, they do not interfere with the electronic communication between the ACE2 and the S protein.
On the other hand, due to its high electrophilicity $(4.40 \mathrm{eV})$ and low nucleophilicity value $(2.07 \mathrm{eV})$, iodine acts as an electron scavenger for the $\mathrm{S}$ protein. Iodine protects ACE2 from attack by $\mathrm{S}$ protein. Finally, selenodiglutathione interacts with $\mathrm{S}$ protein and keeps ACE2 shielded (see Figure $5)$.

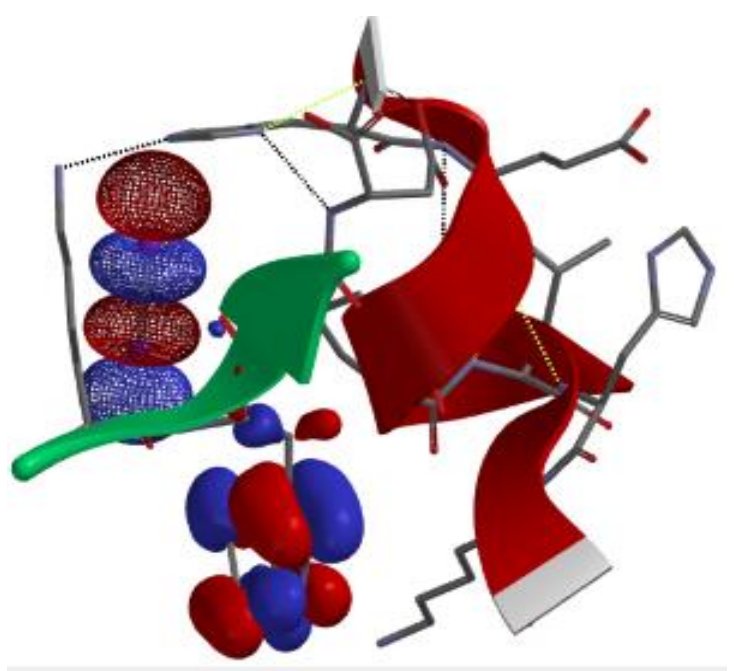

Figure 2. Iodine (Ball and spoke model) exhausts the $\mathrm{S}$ protein's electron donor properties by acting as a durable electron sink (scavenger) that protects the ACE2. Dotted lines represent the hydrogen bonds

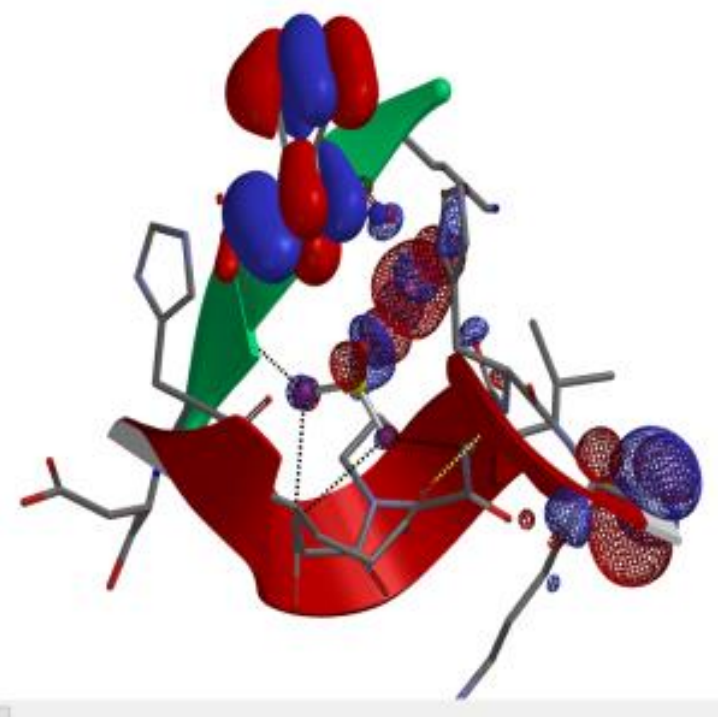

Figure 3. Copper sulfate acting as an electron sink of the $S$ protein (tube) in the presence of ACE2 (the electrophile, tube). However, the formed stable complex has a $\mathrm{BE}=-30.83 \mathrm{kcal} / \mathrm{mol}$ 
This trend points to the importance of iodine and selenodiglutathione as the most effective materials for protecting ACE2 from the attack of the $\mathrm{S}$ protein. Copper sulfate showed remarkable electron sink property but cannot preserve electronic communications between the $\mathrm{S}$ protein and the ACE2, as shown in Figure 3. Moreover, none of the other organometallics or sodium selenite tested suppressed the nucleophilicity of the S protein. Thus, it was evident that the $S$ protein becomes an inert species towards ACE2 in the presence of drugs such as molecular iodine or organometallic selenodiglutathione medication. More to mention is that although iodine and selenodiglutathione strengthen the stability of the adduct, each drug turns the $\mathrm{S}$ protein or ACE2 into an inert species. Consequently, the intermolecular electronic interactions between the species play a crucial role in deactivating one of the reactants' electronic properties.

Noteworthy, mentioning that the presence of any of the following drugs: selenomethionine, sodium selenite, selenodiglutathione, magnesium Lthreonate, or selenodiglutathione does not prevent the interelectronic interactions between ACE2 and S proteins, indicating that the ACE2 is still suffering by interactions with the $\mathrm{S}$ protein. In other words, these drugs mentioned above did not prevent the ACE2 - S proteins from direct electronic communications.

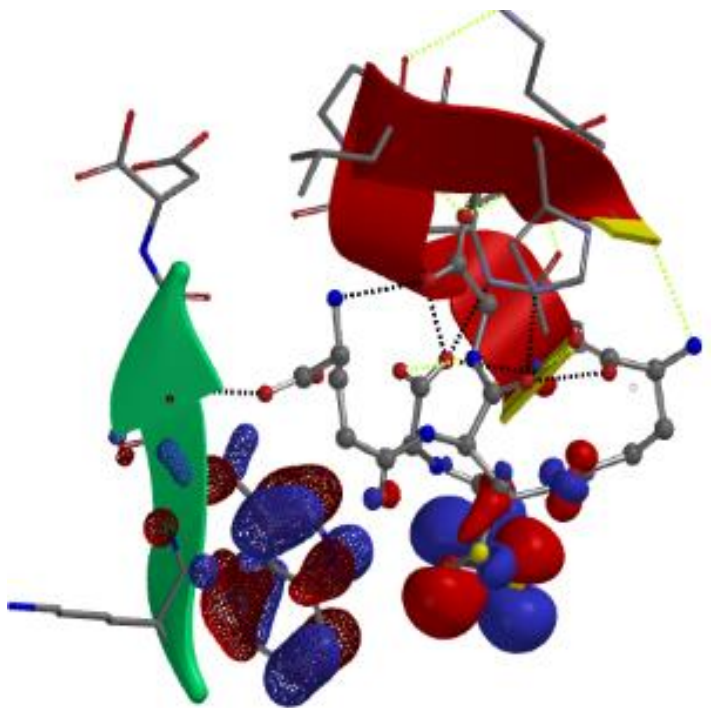

Figure 4. Selenodiglutathione (ball and spoke) interacts with $\mathrm{S}$ protein and shields the ACE2

Iodine has been exploited as a prophylactic and therapeutic agent in treating diseases caused by bacteria, viruses, and fungi, and sanitizing eating utensils. Iodine kills within seconds bacteria, viruses $[33,34]$, fungi, protozoa, and even spores of bacteria and fungi, including anthrax spores. Iodine has been used successfully and efficiently against influenza, herpes, smallpox, and chicken poxviruses [34]. Moreover, recent research reported on, to some extent, similar methodology [35].

Table 3. Reactivity indices (eV) of a) Drug- $\beta_{6} \mathrm{~S}$ protein, b) Drug - ACE2, and c) Drug-ACE2- $\beta_{6} \mathrm{~S}$ protein adducts and their binding energies (BE in $\mathrm{kcal} / \mathrm{mol}$ ) a)

\begin{tabular}{cccccccc}
\hline DRUGS- $\beta_{6}$ & E HOMO & E LUMO & $\boldsymbol{\mu}$ & $\eta$ & $\boldsymbol{\omega}$ & $\mathrm{N}$ & $\mathrm{BE}$ \\
remdesivir & -7.84 & 0.34 & -3.75 & 4.09 & 1.72 & 3.35 & -4.70 \\
\hline IODINE & -7.80 & -1.90 & -4.85 & 2.95 & 3.99 & 3.39 & -7.14 \\
ACE2 & -7.87 & 0.79 & -3.54 & 4.33 & 1.45 & 3.32 & -11.38 \\
CuSO $_{4}$ & -7.87 & 1.11 & -3.38 & 4.49 & 1.27 & 3.32 & -50.90 \\
selenodiglutathione & -7.83 & -5.99 & -6.91 & 0.92 & 25.95 & 3.36 & -52.38 \\
\hline & & $\mathrm{b})$ & & & & & \\
\hline DRUG-ACE2 & E HOMO & E LUMO & $\boldsymbol{\mu}$ & $\eta$ & $\boldsymbol{\omega}$ & $\mathrm{N}$ & $\mathrm{BE}$ \\
\hline remdesivir & -7.86 & 0.45 & -3.71 & 4.16 & 1.65 & 3.33 & 7.02 \\
\hline IODINE & -7.96 & -1.92 & -4.94 & 3.02 & 4.04 & 3.23 & -4.08 \\
CuSO 4 & -8.06 & 1.06 & -3.5 & 4.56 & 1.34 & 3.13 & -37.47 \\
selenodiglutathione & -7.73 & -6.17 & -6.95 & 0.78 & 30.96 & 3.46 & -37.77 \\
\hline & & $\mathrm{c})$ & & & & & \\
\hline DRUG-ACE2- $\beta_{6}$ & $\mathrm{E} \mathrm{HOMO}$ & $\mathrm{E} \mathrm{LUMO}$ & $\boldsymbol{\mu}$ & $\eta$ & $\boldsymbol{\omega}$ & $\mathrm{N}$ & $\mathrm{BE}$ \\
\hline remdesivir & -7.87 & 0.18 & -3.85 & 4.03 & 1.84 & 3.32 & -32.15 \\
\hline IODINE & -7.86 & -1.92 & -4.89 & 2.97 & 4.03 & 3.33 & -33.90 \\
CuSO & -7.83 & 0.93 & -3.45 & 4.38 & 1.36 & 3.36 & -64.33 \\
selenodiglutathione & -7.78 & -6.25 & -7.02 & 0.77 & 32.16 & 3.41 & -73.24 \\
\hline
\end{tabular}

Egypt. J. Chem. 64, No. 2 (2021) 
Finally, we considered the interactions of the three promising drugs mentioned above, with the betasheet sequence $\left(\beta_{6}\right)$ that contains most of the contacting strand of SARS-CoV-2 that binds to ACE2 [19]. Inspecting the results summarized in Table 3, we noticed that iodine's adducts with both $\beta_{6}$ or ACE2 are of less stability than copper sulfate, selenodiglutathione, and ACE2. Remdesivir behaves similarly. Interestingly, we found that the adduct's stability between the ACE2- $\beta_{6}$ is less stable $(\mathrm{BE}=-$ $11.38 \mathrm{kcal} / \mathrm{mol}$, Table 3) than ACE2 - SARS-CoV S protein $(-37.76 \mathrm{kcal} / \mathrm{mol}$, see Table 2$)$. A possible

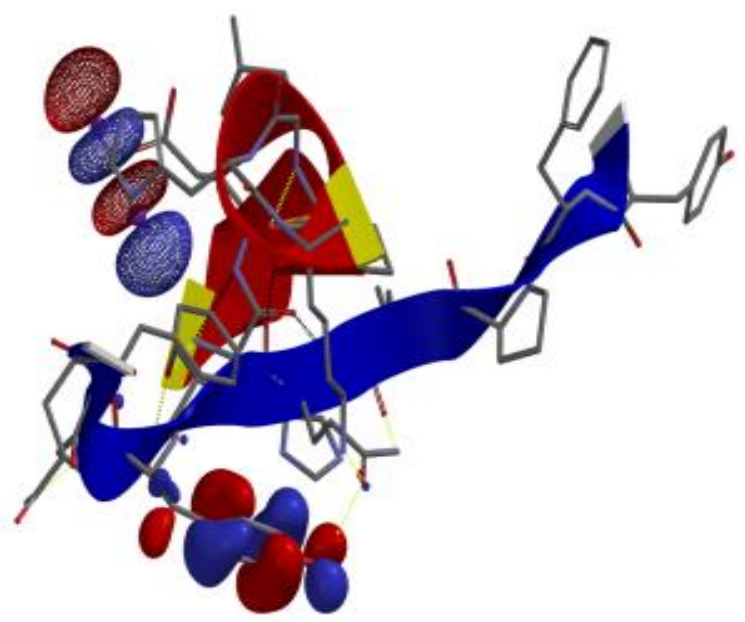

lodine

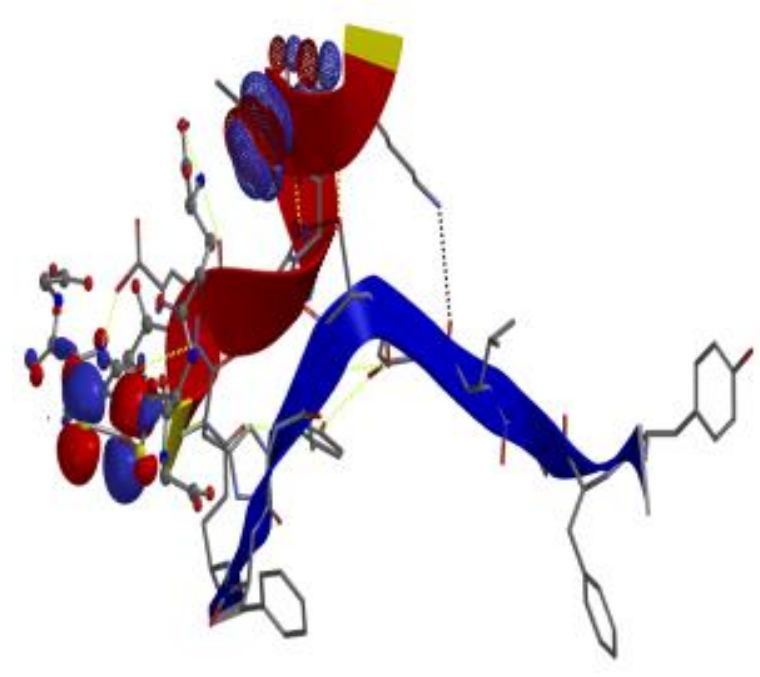

Selenodiglutathione explanation we may propose is that the extra stability of the adduct is due to a more concentrated electron density on a smaller volume $S$ protein sequence of SARS-CoV relative to the $\beta_{6}$ of SARS-CoV-2. We spotted that in the stable complexes formed in the presence of any of the three materials reflected the role of drugs in stabilizing the $\beta_{6}$-ACE2 adduct. This extra stability was concurrent with prohibiting the electronic communications between the $\beta_{6}$ and the ACE2, as shown in Figure 5. A similar explanation discussed above using the reactivity indices we reported in Table 3 is still valid.

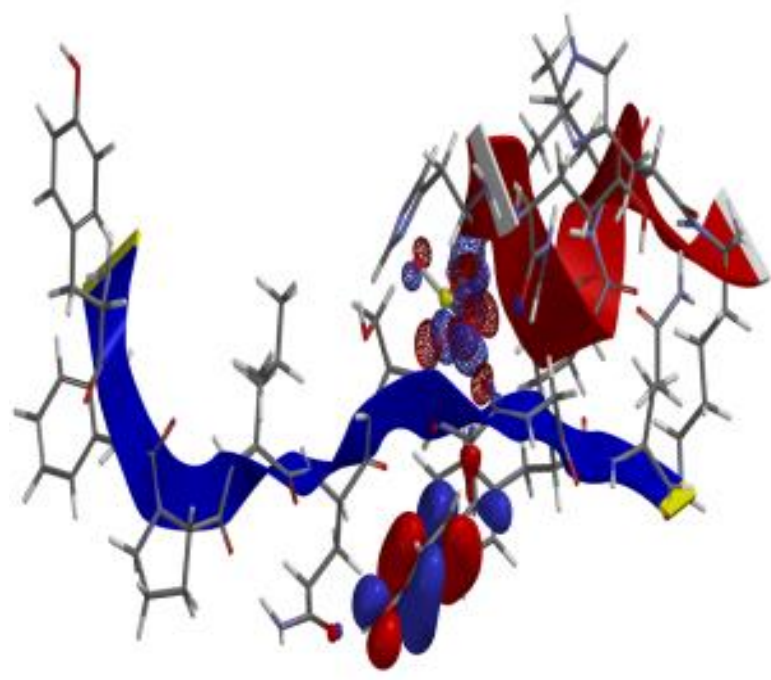

Copper sulfate

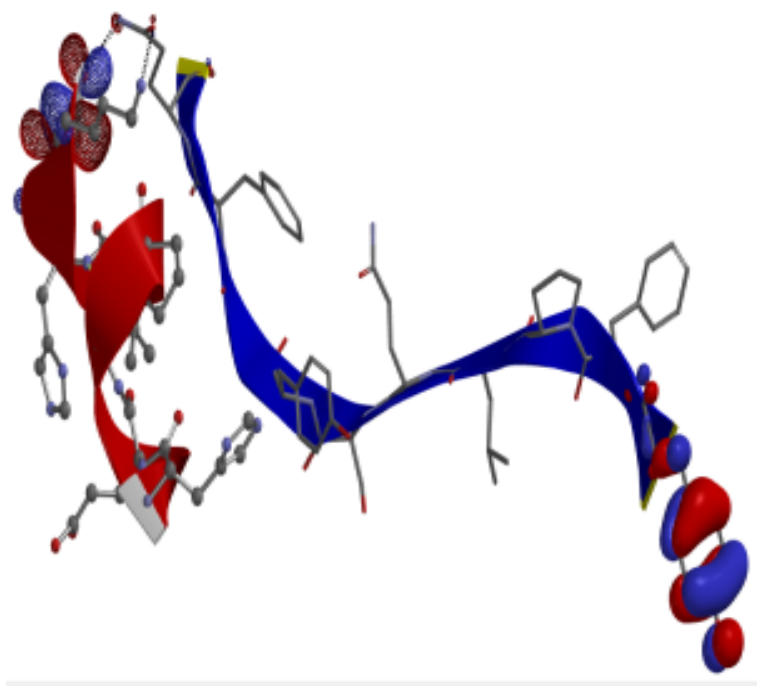

ACE2 $-\boldsymbol{\beta}_{6}$

Figure 5. The complexes formed between the medications and the ACE2- $\beta_{6} \mathrm{~S}$ protein adducts.

\section{Conclusions}

Egypt. J. Chem. 64, No. 2 (2021) 
As a first step towards the identification of drugs that could be used in treatments against COVID-19, we simulated the interactions of model pure peptides that we have chosen to represent the $S$ protein of SARSCoV and SARS-CoV-2 and the ACE2 enzyme with seven inorganic and organometallic ligands that are found in some food supplements. We studied copper sulfate, selenodiglutathione, sodium selenite, selenomethionine, iodine, magnesium L-threonate, and zinc gluconate. We calculated the binding energies of these drug materials with both ACE2 and $\mathrm{S}$ proteins and indicating exothermic reactions. Adduct formed with selenomethionine, or with zinc gluconate molecules with the ACE2 - S protein are of lower stability than that of the ACE2 - S protein adduct.

Interestingly, the S proteins - ACE2 interelectronic interactions were suppressed because of the potent electron donor ligand of selenodiglutathione. The ligand is considered as an electron shielding agent or protection agent for ACE2. On the other hand, the iodine molecule exhausts the $\mathrm{S}$ protein's electron donor properties (SARS-CoV and SARS-CoV-2) by acting as a durable electron sink. The electrophilicity and nucleophilicity indices were successfully used to predict and explain the interacting molecules' reactivity. The results obtained led us to conclude that using iodine, selenodiglutathione, or remdesivir effectively neutralizes the influence of the $\mathrm{S}$ protein on ACE2. Based on the computational predictions reached, in vitro, and in vivo, verification is highly required.

We reasonably assumed that these inorganic or organometallic food supplements would impact specifically the protein/protein interaction here modeled by significant portions of the two proteins, which are reported as responsible for the communications.

As a supportive guide to our proposed methodology, we similarly simulated the interactions between remdesivir and the protein/protein. The experimental antiviral remdesivir assisted people with COVID-19 recover quicker, according to partial data released from a pilot led by the US National Institute of Allergy and Infectious Diseases. The data were adequate for the US Food and Drug Administration, allowing the experimental drug an emergency use authorization (EUA). This status will permit it to be used by doctors treating COVID-19 and be added to government supplies.

\section{Conflict of interests}

There are no conflicts of interest to declare.

\section{Data availability}

All data are available to share upon request from the corresponding author.

\section{References}

1. Bailey R.L., West K.P., Jr., Black R.E., The epidemiology of global micronutrient deficiencies, Ann Nutr Metab 66 Suppl 2 (2015) 22-33.

2. McMillan D.C., Maguire D., Talwar D., Relationship between nutritional status and the systemic inflammatory response: micronutrients, Proc Nutr Soc 78(1) (2019) 56-67.

3. Jayawardena R., Sooriyaarachchi P., Chourdakis M., Jeewandara C., Ranasinghe P., Enhancing immunity in viral infections, with special emphasis on COVID-19: A review, Diabetes Metab Syndr 14(4) (2020) 367-382.

4. Rashed M.N., The role of trace elements on hepatitis virus infections: a review, J Trace Elem Med Biol 25(3) (2011) 181-7.

5. Li C., Li Y., Ding C., The Role of Copper Homeostasis at the Host-Pathogen Axis: From Bacteria to Fungi, Int J Mol Sci 20(1) (2019).

6. Read S.A., Obeid S., Ahlenstiel C., Ahlenstiel G., The Role of Zinc in Antiviral Immunity, Adv Nutr 10(4) (2019) 696-710.

7. Rayman M.P., Selenium and human health, Lancet 379(9822) (2012) 1256-68.

8. Liu G, Weinger JG, Lu ZL, et al. Efficacy and Safety of MMFS-01, J Alzheimers Dis. 2016, 49(4), 971

9. Gershenfeld L., Iodine as a virucidal agent, J Am Pharm Assoc Am Pharm Assoc 44(3) (1955) 177-82.

10. Gershenfeld L., Povidone-iodine (PVP-I) as a trichomonacide, Am J Pharm Sci Support Public Health 134 (1962) 324-31.

11. Gershenfeld L., Povidone-iodine (PVP-I) as a vaginal microbicide, Am J Pharm Sci Support Public Health 134 (1962) 278-91.

12. Gershenfeld L., Povidone-iodine as a sporicide, Am J Pharm Sci Support Public Health 134 (1962) 78-81.

13. Gershenfeld L., Flagg W.B., Witlin B., Iodine as a tuberculocidal agent, Mil Surg 114(3) (1954) 172-83.

14. Gershenfeld L., Witlin B., Iodine as an antiseptic, Ann N Y Acad Sci 53(1) (1950) 17282.

15. Eggers M., Infectious Disease Management and Control with Povidone Iodine, Infect Dis Ther 8(4) (2019) 581-593.

16. Derry D., Iodine: the Forgotten Weapon Against Influenza Viruses, Thyroid Science 4(9) (2009) 1-5.

17. Sabry Abdel-Mottaleb M., and Yousra AbdelMottaleb, In Search for Effective and Safe Drugs Against SARS-CoV-2: Part I] Simulated Interactions Between Selected Nutraceuticals, 
ACE2 Enzyme and S Protein Simple Peptide Sequences., ChemRxiv (2020).

18. Smith M.S., Jeremy C. , Repurposing Therapeutics for COVID-19: SupercomputerBased Docking to the SARS-CoV-2 Viral Spike Protein and Viral Spike Protein-Human ACE2 Interface, ChemRxiv (2020).

19. Lan J., Ge J., Yu J., et al. Structure of the SARS-CoV-2 spike receptor-binding domain bound to the ACE2 receptor. Nature 581, 215220 (2020)

20. Geerlings P., De Proft F., Langenaeker W., Conceptual density functional theory, Chem Rev 103(5) (2003) 1793-873.

21. Fleming I., Frontier Orbitals and Organic Chemical Reactions, John Wiley and Sons, New York, 1976.

22. Domingo L. R., Chamorro E., Perez P., Understanding the reactivity of captodative ethylenes in polar cycloaddition reactions. A theoretical study, J Org Chem 73(12) (2008) 4615-24.

23. Domingo L. R., Rios-Gutierrez M., Perez, P. Applications of the Conceptual Density Functional Theory Indices to Organic Chemistry Reactivity, Molecules 21(6) (2016).

24. Domingo L. R., Molecular Electron Density Theory: A Modern View of Reactivity in Organic Chemistry, Molecules 21(10) (2016).

25. Domingo L. R., A new $\mathrm{C}-\mathrm{C}$ bond formation model based on the quantum chemical topology of electron density, RSC Adv. 4 (2014) 3241532428.

26. Zielinski F., Condensed descriptors for reactivity: a methodological study, Chemical Physics Letters 527 (2012) 67-72.

27. Wadt P., Ab initio effective core potentials for molecular calculations - potentials for the transition-metal atoms $\mathrm{Sc}$ to $\mathrm{Hg}$, J. Chem. Phys. 82 (1985) 270-83.
28. Chai J.D., Long-range corrected hybrid density functionals with damped atom-atom dispersion corrections, Physical Chemistry Chemical Physics 10(44) (2008) 6615-6620.

29. Cossi M., Scalmani G., Barone V., Energies, structures, and electronic properties of molecules in solution with the C-PCM solvation model, J. Comput. Chem. 24(6) (2003) 669-681.

30. Li W., Moore M.J., Vasilieva N., Sui J., Wong S.K., Berne M.A., Somasundaran M., Sullivan J.L., Luzuriaga K., Greenough T.C., Choe H., Farzan M., Angiotensin-converting enzyme 2 is a functional receptor for the SARS coronavirus, Nature 426(6965) (2003) 450-4.

31. Courtney Mycroft-West, Dunhao Su, Stefano Elli, Scott Guimond, Gavin Miller, Jeremy Turnbull, Edwin Yates, Marco Guerrini, David Fernig, Marcelo Lima, M. Skidmore, The 2019 coronavirus (SARS-CoV-2) surface protein (Spike) S1 Receptor Binding Domain undergoes conformational change upon heparin-binding, BioRxiv (2020).

32. Li Z., Tomlinson A.C., Wong A.H., Zhou D., Desforges M., Talbot P.J., Benlekbir S., Rubinstein J.L., Rini J.M., The human coronavirus HCoV-229E S-protein structure and receptor binding, Elife 8 (2019).

33. Carroll B., The relative germicidal activity of triiodide and diatomic iodine, J. Bacteriol. (69) (1955) 413-417

34. Gershenfeld L., Iodine. In Disinfection, Sterilization, and Preservation., Les \& Febiger, Philadelphia, 1977.

35. Ece A. and Pejin B., A computational insight into acetylcholinesterase inhibitory activity of a new lichen depsidone, Journal of Enzyme Inhibition and Medicinal Chemistry 2015, 30(4), 528-532.

\footnotetext{
SARS- تأثير مكملات المغنيسيوم والزنك والسيلينيوم والنحاس واليود على فيروسات SARS-CoV-2 ومكون SOV

محمد صبري أحمد عبد المطلب1، يسرا محمد صبري عبد المطلب2

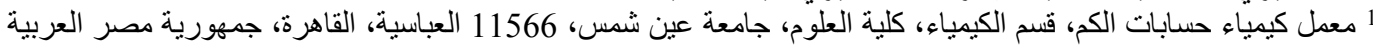

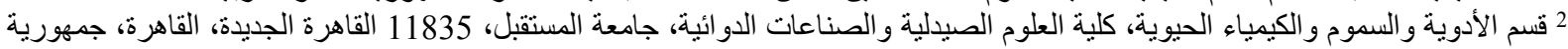
مصر العربية

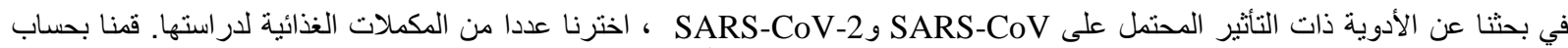

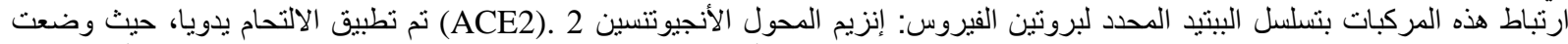

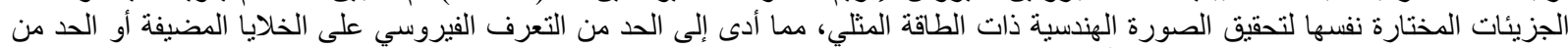

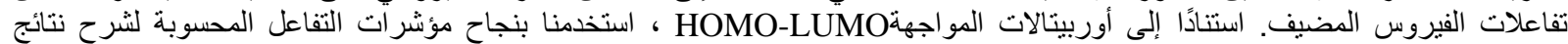

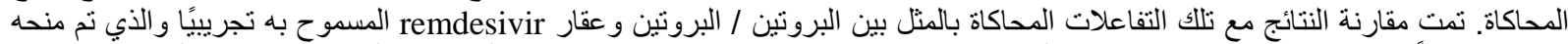

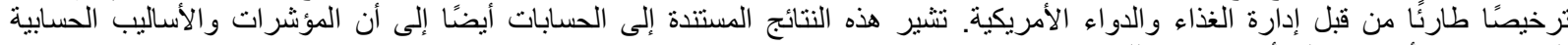
البسيطة يمكن أن تثير بن فيل إلى أدوية واعدة للمساعدة في مكافحة
} 